\title{
Indonesian Seas \\ Finestructure Variability
}

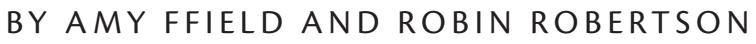

The Indonesian seas contain evidence of enhanced vertical mixing. Coupled with the highly stratified tropical thermocline, this enhanced mixing implies large vertical fluxes of heat and buoyancy from the ocean-atmosphere boundary downward deep into the water column. To accurately predict climate change requires quantifying this vertical mixing and its temporal and spatial variability, because these fluxes help regulate ocean heat storage and thermohaline circulation.

\section{Indonesian Seas}

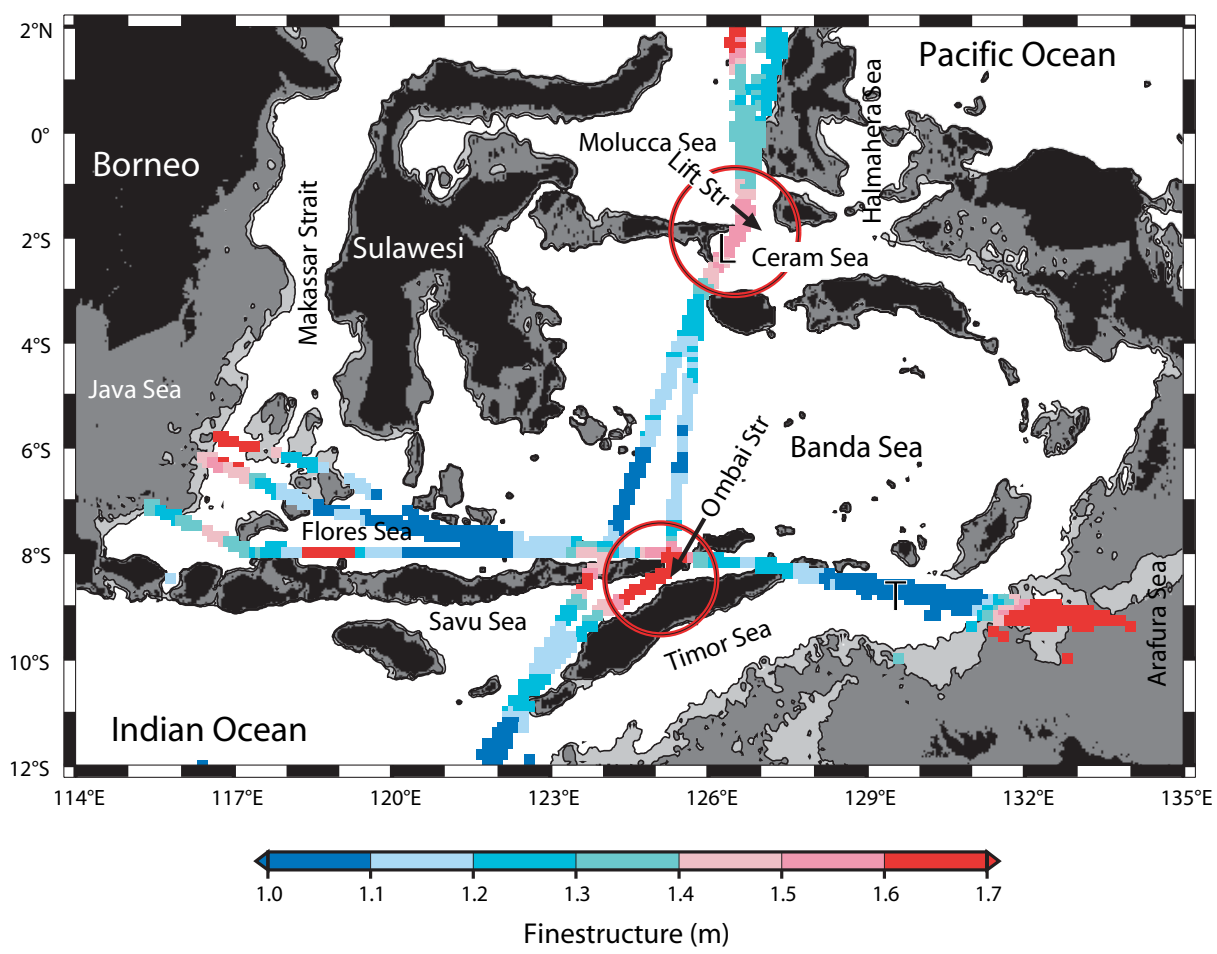

Figure 1. The finestructure in the Indonesian seas region averaged over 18 years between 100 and 300 $\mathrm{m}$ depths and plotted along the XBT transects (5359 profiles). The finestructure is generally largest near topography (e.g., near coastlines, over shallow shelves, and within straits). Two notable regions are enclosed by large red circles, the Lifamatola Strait, which has average finestructure values greater than $1.5 \mathrm{~m}$ despite being within a deep and broad strait, and the Ombai Strait, which is also within a deep strait and has the largest finestructure values (greater than $2.0 \mathrm{~m}$ ). Bathymetry is grey shaded and contoured for 100 and $300 \mathrm{~m}$ depths and is solid white for depths greater than $300 \mathrm{~m}$. The finestructure data are smoothed heavily by a $3^{\circ}$ filter. " $\mathrm{L}$ " and " $\mathrm{T}$ " mark the locations of the two example XBT profiles shown in Figure 3.

We use 18 years of temperature stratification data from expendable bathythermographic (XBT) probes to show that the finestructure associated with mixing reveals clear enhancement near topography and significant temporal variability. We observed a 33 percent decrease in finestructure in the upper water column during El Niño years, suggesting reduced mixing, whereas during La Niña years, an 18 percent increase in finestructure suggested enhanced mixing.

Within the Indonesian seas, incoming stratified Pacific Ocean waters are radically altered by vertical mixing such that the distinctive salinity maxima originating from the North Pacific (salinity of 34.8 at $100 \mathrm{~m}$ ) and the South Pacific (salinity of 35.4 at $150 \mathrm{~m}$ ) eventually disappear. Consequently, by the time the throughflow waters leave the Indonesian seas to enter the Indian Ocean, they carry homogeneous salinities (34.6) throughout the upper thermocline. In the upper thermocline, the basin-averaged, time-averaged estimates of vertical

Amy Ffield (ffield@esr.org) is Senior Scientist, Earth \& Space Research, Upper Grandview, NY, USA. Robin Robertson (rroberts@ldeo.columbia.edu) is Doherty Associate Research Scientist, LamontDoherty Earth Observatory of Columbia University, Palisades, NY, USA. 
mixing inferred from these stratification changes in the water column are high, on the order of $1 \times 10^{-4} \mathrm{~m}^{2} \mathrm{~s}^{-1}$ (Hautala et al., 1996; Ffield and Gordon, 1996). In contrast, two weeks of microstructure measurements in the Banda Sea yield a vertical mixing estimate typical of relatively low open-ocean values, $9 \times 10^{-6} \mathrm{~m}^{2} \mathrm{~s}^{-1}$, between 20 and $300 \mathrm{~m}$ depth (Alford et al., 1999). In this issue, 2-D barotropic tides (Ray et al.) and 3-D baroclinic tides (Robertson and Ffield) are reported, in part, to begin to assess the role of tides in vertical mixing throughout the Indonesian seas. For the small southern Makassar Strait region, a 2-D nonhydrostatic model produces tidally generated internal waves that induce vertical mixing as high as $6 \times 10^{-3} \mathrm{~m}^{2} \mathrm{~s}^{-1}$ (Hatayama, 2004).

To put the inferred, modeled, and measured vertical mixing estimates into a larger basin-wide, time-varying context, we present an overview of the temperature finestructure and its variability in the Indonesian Seas. The 1985 to 2003 data set is compiled from 5359 XBT probes deployed monthly along commercial shipping lines (Figure 1) by volunteer observers as part of the upper-ocean observing system network (Wijffels and Meyers, 2004). Often, observations of density inversions and internal wave vertical strain (the gradient of isopycnal displacement) in vertical profile data are used to estimate diapycnal turbulent mixing (e.g., Finnigan et al., 2002). However, the limited accuracy $\left( \pm 0.1^{\circ} \mathrm{C}\right)$ of the XBT temperature values (aside from the lack of concurrent salinity values) and the large temporal and spatial distribution of the XBT profiles prevent making reliable estimates of mixing. Previously, XBT data have

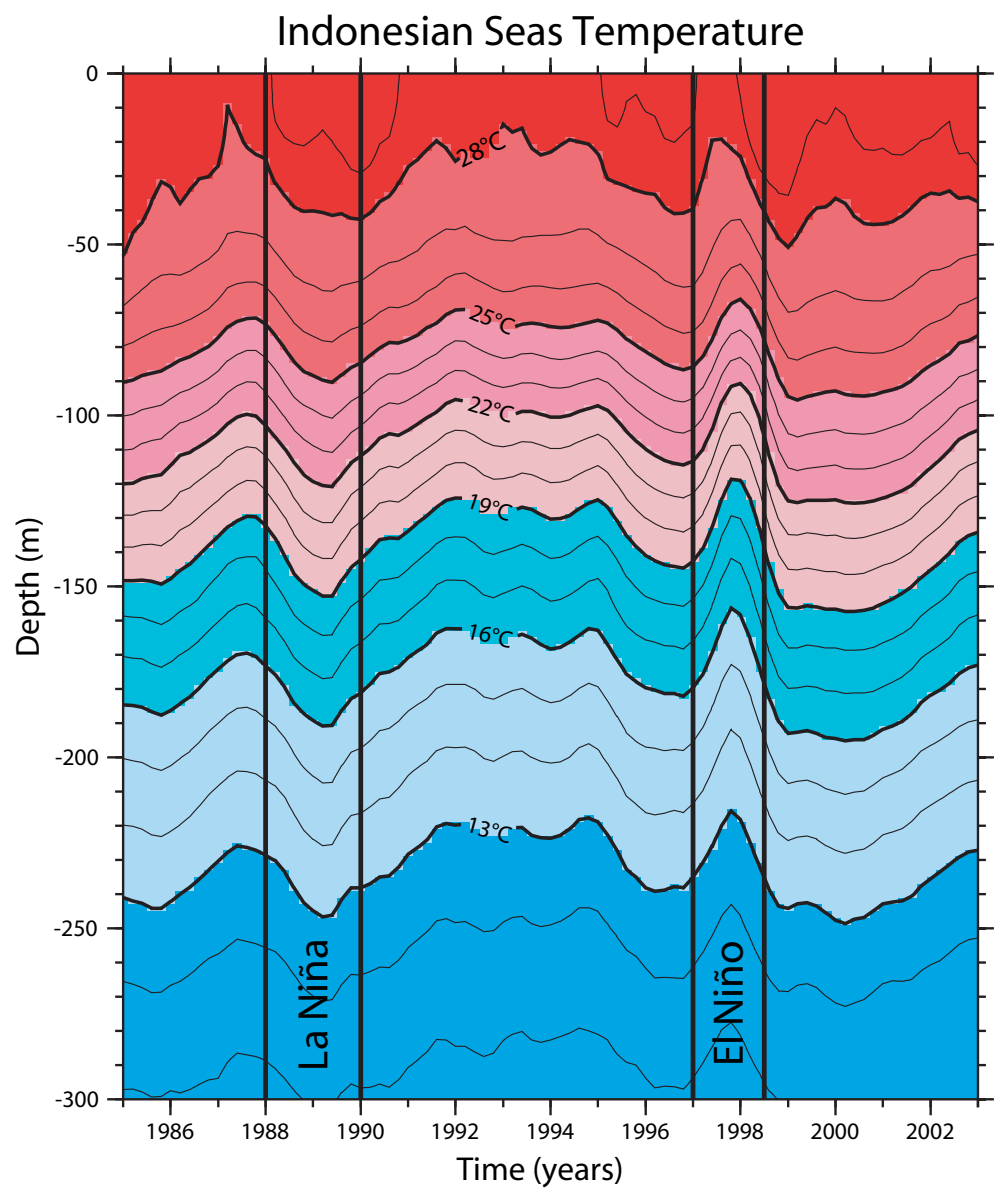

Figure 2. The temperature time-depth section averaged over the $114^{\circ} \mathrm{E}$ to $135^{\circ} \mathrm{E}$ and $12^{\circ} \mathrm{S}$ to $2^{\circ} \mathrm{N}$ Indonesian seas region. ENSO variability is easily observed from the ocean surface down to the bottom of the XBT profiles $\sim 760 \mathrm{~m}$; this section only shows the upper $300 \mathrm{~m}$ of the water column in order to expand the mid-thermocline levels, which have the largest ENSO signal at $150 \mathrm{~m}$. Ocean temperatures throughout the Indonesian seas (and the western Pacific Ocean) are cooler during El Niño years and warmer during La Niña years; for example, in this section at $150 \mathrm{~m}$, they attain temperatures $\sim 1.5^{\circ} \mathrm{C}$ cooler than usual during the El Niño of 1997-1998 when the thermocline shallows and temperatures $\sim 1.25^{\circ} \mathrm{C}$ warmer than usual during the La Niña of 1988-1989 when the thermocline deepens. The data are smoothed by a $20-\mathrm{m}$ vertical filter and then a 1 -yr horizontal filter.

been used to show the El Niño-Southern Oscillation (ENSO) temperature variability in the Indonesian seas' thermocline (Bray et al., 1996), which has been observed in other temperature data sets as well (Sprintall et al., 2003; Ffield et al., 2000). Here, this time variability can be easily observed by spatially averaging all the temperature profiles in the $114^{\circ} \mathrm{E}$ to $135^{\circ} \mathrm{E}$ and $12^{\circ} \mathrm{S}$ to $2^{\circ} \mathrm{N}$ Indonesian seas region and constructing a single time-depth section of temperature (Figure 2). Ocean temperatures throughout the Indonesian seas (and the western Pacific Ocean) are cooler during El Niño years and warmer during La Niña years throughout the water column, with a maximum signal around $150-\mathrm{m}$ 
depth. At $150 \mathrm{~m}$, during the El Niño of 1997-1998, the temperatures are $\sim 1.5^{\circ} \mathrm{C}$ cooler than usual when the thermocline shallows; during the La Niña of 1988-1989, the temperatures are $\sim 1.5^{\circ} \mathrm{C}$ warmer than usual when the thermocline deepens.

Visually examining two temperature profiles reveals the finestructure and how it may vary. A Lifamatola Strait temperature profile (Figure 3a) reveals considerable temperature structure at a range of vertical scales from 2-100 $\mathrm{m}$ throughout the profile; for example, between 50 and $100 \mathrm{~m}$, there is a distinct $25^{\circ} \mathrm{C}, 50 \mathrm{~m}$ vertical step feature in addition to nearby smaller-scale bumps and wiggles in the profile. In contrast, a relatively quiescent

Temperature and Finestructure Profiles
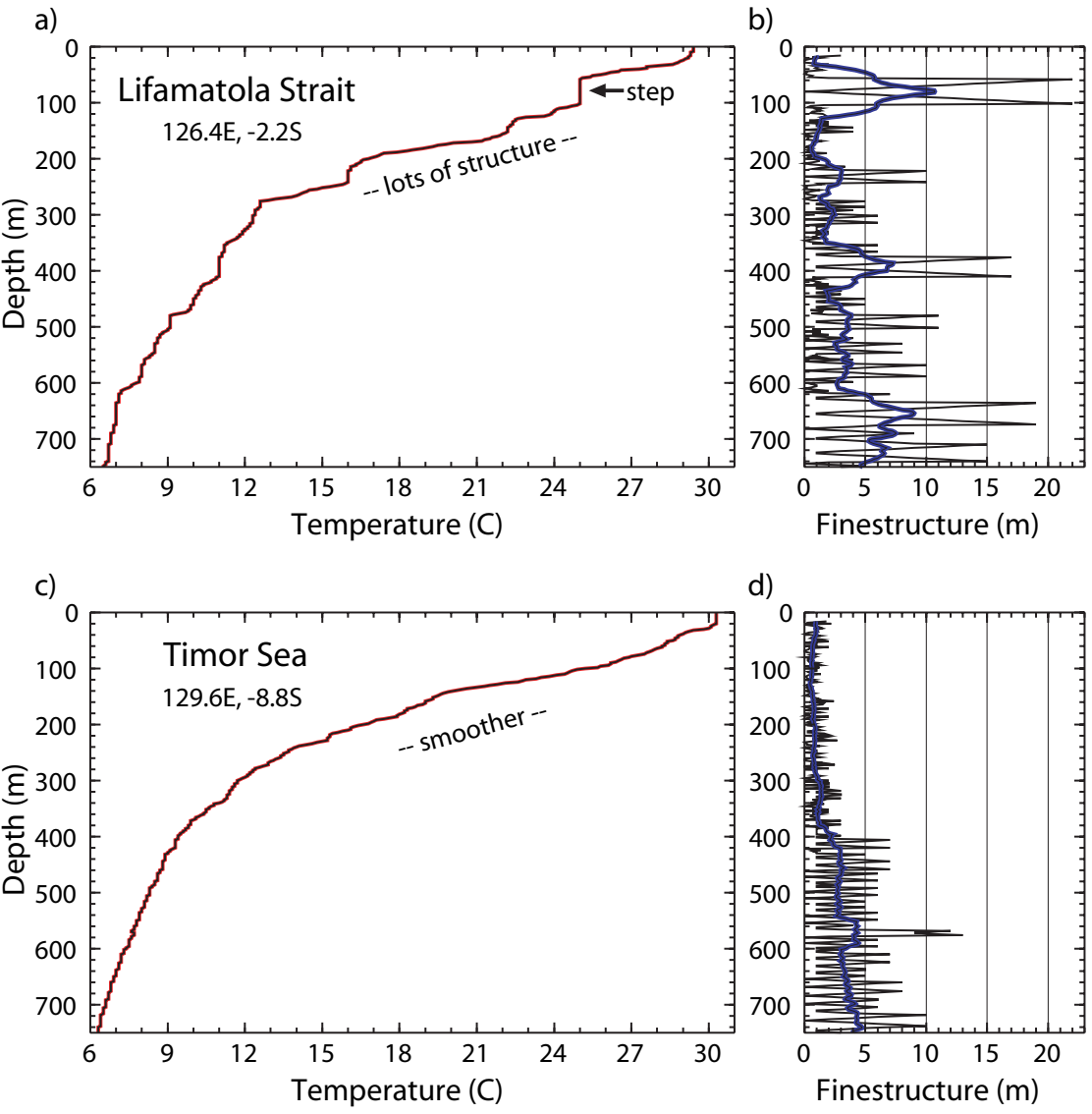

Figure 3. Indonesian seas temperature and finestructure profiles contrasting the active Lifamatola Strait with the relatively quiescent Timor Sea. The Lifamatola Strait XBT temperature profile (a) reveals considerable structure at all depths and vertical scales. In contrast, the Timor Sea XBT temperature profile (c) is relatively smooth at all depths. Regions with more finestructure may have more mixing. To quantify the finestructure observed in a XBT temperature profile, the magnitude of the isotherm vertical displacements (in meters) are determined relative to the profile smoothed by a $10-\mathrm{m}$ block running mean. Calculated in this way, the finestructure variability of the Lifamatola Strait profile (b) is large, with a 50 to $300 \mathrm{~m}$ depth average of $3.4 \mathrm{~m}$, reflecting the considerable vertical temperature structure observed in the temperature profile. In contrast, the Timor Sea finestructure variability (d) is smaller, with a 50 to $300 \mathrm{~m}$ depth average of only $0.7 \mathrm{~m}$, reflecting the smoother temperature profile. The $50 \mathrm{~m}$ running block average of the finestructure is shown in blue.

Timor Sea temperature profile (Figure $3 c$ ) is relatively smooth throughout. To quantify the finestructure observed in an XBT temperature profile, we determined the magnitudes of the isotherm vertical displacements (in meters) relative to the profile smoothed by a $10-\mathrm{m}$ block running mean. The focus is on finestructure at 2 to $10 \mathrm{~m}$ scales to avoid introducing biases from larger-scale circulation-related changes in the thermocline. Calculated in this way, the finestructure variability in the Lifamatola Strait profile (Figure $3 \mathrm{~b}$ ) is large, with a 50 to $300 \mathrm{~m}$ depth average of $3.4 \mathrm{~m}$, reflecting the considerable vertical temperature structure observed in the temperature profile. In contrast, the Timor Sea finestructure variability (Figure 3d) is smaller, with a 50 to 300 $\mathrm{m}$ depth average of only $0.7 \mathrm{~m}$, reflecting the smoother temperature profile.

To assess the geographic variability, we temporally averaged all 18 years of finestructure results between 100 and 300 $m$ depths and plotted them on the XBT transect map (Figure 1). The finestructure is generally largest near topography (e.g., near coastlines, over shallow shelves, and within straits). Two notable regions are the Lifamatola Strait near $126^{\circ} \mathrm{E}, 2^{\circ} \mathrm{S}$, which has average finestructure values greater than $1.5 \mathrm{~m}$ despite being within a deep and broad strait, and the Ombai Strait near $125^{\circ} \mathrm{E}, 8^{\circ} \mathrm{S}$, which is also within a deep strait and has the largest average finestructure values (greater than 2.0 $\mathrm{m})$. When all these data are compiled as a function of distance to the nearest 100-m topography (not shown), a clear relation is evident; the highest finestructure values are adjacent to topography and drop off smoothly with distance.

To assess the temporal variability, we spatially averaged all the finestructure 
results into single time series. Using examples highlighting different depths of the water column, the time series (Figure 4) of temperature at $150 \mathrm{~m} \mathrm{(a),} \mathrm{finestruc-}$ ture at $30 \mathrm{~m} \mathrm{(b)}$, and finestructure at 550 $\mathrm{m}(\mathrm{c})$ all reveal ENSO variability when visually compared to the Niño 3 index (d). During the El Niño of 1997-1998, temperatures are cooler throughout the water column (Figure 2) and the 150$\mathrm{m}$ mid-thermocline temperature is 8 percent cooler than average (Figure 4a). However, the finestructure is 33 percent less than average at $30 \mathrm{~m}$ in the upper thermocline (Figure 4b), but 29 percent greater than average at $550 \mathrm{~m}$ in the lower thermocline (Figure 4c). This result can be explained by the increased (decreased) vertical temperature stratification in the upper $100 \mathrm{~m}$ (below $100 \mathrm{~m}$ ) during an El Niño (not shown). There is also considerable monsoonal variability (not shown) in the finestructure, with much higher values in the upper $100 \mathrm{~m}$ during the strong June, July, and August monsoonal winds. These finestructure results can be used to put vertical mixing estimates into a geographic and temporal framework within the Indonesian seas.

\section{ACKNOWLEDGEMENTS}

This project was supported by the Office of Naval Research, NOOO14-03-1-0423. Lamont-Doherty Earth Observatory contribution number 6820. Earth \& Space Research contribution number 83 . 四

\section{REFERENCES}

Alford, M., M. Gregg, and M. Ilyas. 1999. Diapycnal mixing in the Banda Sea: Results of the first microstructure measurements in the Indonesian throughflow. Geophysical Research Letters 26:2,741-2,744.

Bray, N.A., S. Hautala, J. Chong, and J. Pariwono. 1996. Large-scale sea level, thermocline, and wind variations in the Indonesian through-

\section{Indonesian Seas Time Series}

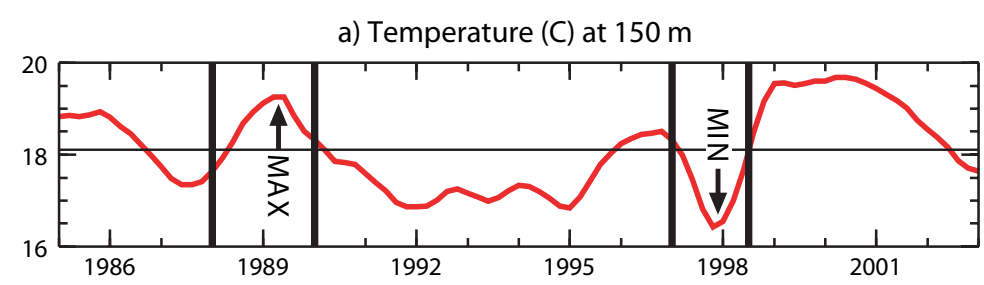

b) Finestructure $(\mathrm{m})$ at $30 \mathrm{~m}$

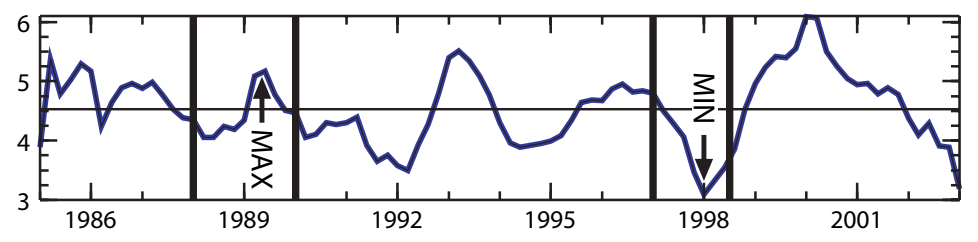

c) Finestructure $(\mathrm{m})$ at $550 \mathrm{~m}$

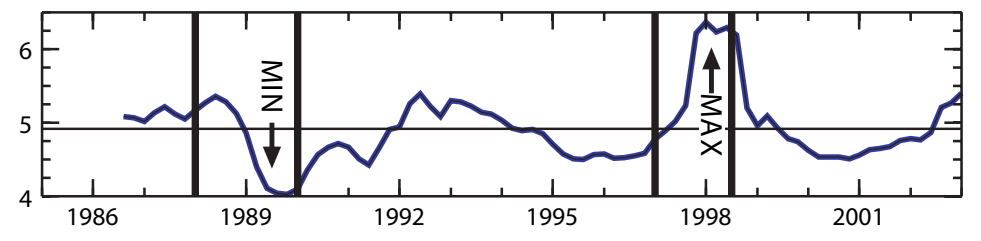

d) Niño 3

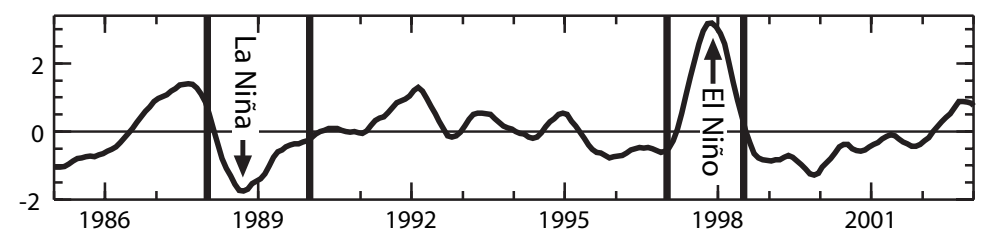

Figure 4. Time series of temperature at $150 \mathrm{~m}$ (a), finestructure at $30 \mathrm{~m}$ (b), and finestructure at $550 \mathrm{~m}$ (c) averaged over the $114^{\circ} \mathrm{E}$ to $135^{\circ} \mathrm{E}$ and $12^{\circ} \mathrm{S}$ to $2^{\circ} \mathrm{N}$ Indonesian seas region. The Niño 3 index is shown for comparison in (d). All the variables reveal ENSO variability. During the El Niño of 1997-1998, the temperature at $150 \mathrm{~m}$ is cooler than average (a), as are all the temperatures throughout the water column (Figure 2). However, the finestructure is less than average at $30 \mathrm{~m}$ in the upper water column (b), but greater than average at $550 \mathrm{~m}$ in the lower water column (c).

flow region. Journal of Geophysical Research 101:12,239-12,254.

Ffield, A., and A. Gordon. 1996. Tidal mixing signatures in the Indonesian Seas. Journal of Physical Oceanography 26:1,924-1,937.

Ffield, A., K. Vranes, A.L. Gordon, R.D. Susanto, and S.L. Garzoli. 2000. Temperature Variability within Makassar Strait. Geophysical Research Letters 27:237-240.

Finnigan, T.D., D.S. Luther, and R. Lukas. 2002. Observations of Enhanced Diapycnal Mixing near the Hawaiian Ridge. Journal of Physical Oceanography 32:2,988-3,002.

Hatayama, T. 2004. Transformation of the Indonesian throughflow water by vertical mixing and its relation to tidally generated internal waves. Journal of Oceanography 60:569-585.

Hautala, S., J. Reid, and N. Bray. 1996. The distribution and mixing of Pacific water masses in the Indonesian seas. Journal of Geophysical Research 101:12,375-12,389.

Sprintall, J., J.T. Potemra, S.L. Hautala, N.A. Bray, and W.W. Pandoe. 2003. Temperature and salinity variability in the exit passages of the Indonesian throughflow. Deep-Sea Research II 50:2,183-2,204.

Wijffels, S., and G. Meyers. 2004. An Intersection of oceanic waveguides: Variability in the Indonesian throughflow region. Journal of Physical Oceanography 34:1,232-1,253. 